\title{
Consumers' estimation of calorie content at fast food restaurants: cross sectional observational study
}

\section{Citation}

Block, Jason P, Suzanne K Condon, Ken Kleinman, Jewel Mullen, Stephanie Linakis, Sheryl Rifas-Shiman, and Matthew W Gillman. 2013. Consumers' estimation of calorie content at fast food restaurants: cross sectional observational study. BMJ : British Medical Journal 346:f2907.

\section{Published Version}

doi:10.1136/bmj.f2907

\section{Permanent link}

http://nrs.harvard.edu/urn-3:HUL.InstRepos:11180458

\section{Terms of Use}

This article was downloaded from Harvard University's DASH repository, and is made available under the terms and conditions applicable to Other Posted Material, as set forth at http:// nrs.harvard.edu/urn-3:HUL.InstRepos:dash.current.terms-of-use\#LAA

\section{Share Your Story}

The Harvard community has made this article openly available.

Please share how this access benefits you. Submit a story.

\section{Accessibility}




\title{
Consumers' estimation of calorie content at fast food restaurants: cross sectional observational study
}

\author{
(c) $(1)(9)$ OPEN ACCESS
}

\author{
Jason P Block assistant professor ${ }^{1}$, Suzanne K Condon director ${ }^{2}$, Ken Kleinman associate professor ${ }^{1}$, \\ Jewel Mullen commissioner ${ }^{3}$, Stephanie Linakis project manager ${ }^{1}$, Sheryl Rifas-Shiman senior \\ analyst ${ }^{1}$, Matthew W Gillman professor ${ }^{14}$
}

${ }^{1}$ Obesity Prevention Program, Department of Population Medicine, Harvard Medical School/Harvard Pilgrim Health Care Institute, 133 Brookline Avenue, Boston, MA 02215, US; 'Bureau of Environmental Health, Massachusetts Department of Public Health, 250 Washington Street, Boston, MA 02108, US; ${ }^{3}$ Connecticut Department of Public Health, 410 Capitol Avenue, Hartford, CT 06134, US; ${ }^{4}$ Department of Nutrition, Harvard School of Public Health, 665 Huntington Avenue, Boston, MA 02115, US

\begin{abstract}
Objective To investigate estimation of calorie (energy) content of meals from fast food restaurants in adults, adolescents, and school age children.

Design Cross sectional study of repeated visits to fast food restaurant chains.

Setting 89 fast food restaurants in four cities in New England, United States: McDonald's, Burger King, Subway, Wendy's, KFC, Dunkin' Donuts.

Participants 1877 adults and 330 school age children visiting restaurants at dinnertime (evening meal) in 2010 and $2011 ; 1178$ adolescents visiting restaurants after school or at lunchtime in 2010 and 2011.

Main outcome measure Estimated calorie content of purchased meals.

Results Among adults, adolescents, and school age children, the mean actual calorie content of meals was 836 calories (SD 465), 756 calories (SD 455), and 733 calories (SD 359), respectively. A calorie is equivalent to $4.18 \mathrm{~kJ}$. Compared with the actual figures, participants underestimated calorie content by means of 175 calories (95\% confidence interval 145 to 205), 259 calories (227 to 291), and 175 calories (108 to 242), respectively. In multivariable linear regression models, underestimation of calorie content increased substantially as the actual meal calorie content increased. Adults and adolescents eating at Subway estimated $20 \%$ and $25 \%$ lower calorie content than McDonald's diners (relative change $0.80,95 \%$ confidence interval 0.66 to $0.96 ; 0.75,0.57$ to 0.99 ).

Conclusions People eating at fast food restaurants underestimate the calorie content of meals, especially large meals. Education of consumers through calorie menu labeling and other outreach efforts might reduce the large degree of underestimation.
\end{abstract}

\section{Introduction}

A recent international policy approach to obesity prevention, driven by the growth in consumption of fast food, is to require restaurants to print calorie content on menus. From 2006 to 2010, many states and municipalities in the United States passed laws on provision of calorie content on restaurant menus. These efforts culminated in the federal Patient Protection and Affordable Care Act of 2010, which included a provision that will require all chain restaurants with more than 20 sites in the US to print calorie contents on menus. These policies were driven by the belief that individuals might consume excess calories when they are eating restaurant meals because of limited awareness of the calorie content. Previous research has shown that adults and children underestimate the calorie content of their meals, often by large amounts. These studies, however, were conducted in experimental settings with no monitoring of consumer choices at actual restaurants, ${ }^{12}$ focused on a narrow range of fast food restaurants in samples with limited racial/ethnic diversity, ${ }^{2}$ or were unable to examine differences between age groups or between fast food restaurant chains. ${ }^{4}$ We quantified the difference between estimated and actual calorie content of meals purchased by adults, adolescents, and school age children at six fast food restaurant chains in four cities in New England, US, and assessed the correlates of underestimation. 


\section{Methods}

\section{Restaurant sample}

We interviewed participants dining at fast food chain restaurants in Boston and Springfield, MA; Providence, RI; and Hartford, CT. We considered for inclusion the 10 chains with the highest sales in the US. For adult and school age children samples, surveyed at dinnertime (evening meal), we interviewed diners at the five chains that had at least two sites in each city and catered to dinnertime meals: McDonald's, Burger King, Wendy's, KFC, and Subway. For the adolescent sample, collected after the school day or at lunchtime, we interviewed diners at the five chains that had at least two sites within one mile $(1.6 \mathrm{~km})$ of a high school in each city. In the Utates, high schools typically include 9 th through 12 th grades with children aged 14-19; however, some schools include children from broader age groups. These restaurants were the same as for the adult/school age children samples except we omitted KFC and added Dunkin' Donuts. We excluded pizza restaurant chains (such as Pizza Hut) because of the difficulty in determining the quantity that an individual bought for personal consumption, and we excluded restaurants that cater primarily to adults (such as Starbucks).

At the time of our data collection, none of the chains in our sample routinely printed calorie contents on menus. The chains presented calorie contents, along with additional nutrition information, on wall posters, food containers, napkins, and cups or on limited menus identifying food choices with less than a specified number of calories. All chains presented comprehensive nutritional information on their websites.

Using restaurant locators on chains' websites, we randomly selected 10 restaurants in each city, stratified by chain, for a total of 40 restaurants for the adult and school age children samples: three McDonald's, three Burger Kings, two Subways, one KFC, and one Wendy's in each city. Of the initial 40 restaurants we selected, we excluded one restaurant because it closed in 2011 and four restaurants in 2010 or 2011 because restaurant management refused to allow us to collect data on restaurant premises and no public sidewalk was available from which to work. We replaced these restaurants through either random selection in 2010 or by selecting the nearest restaurant from the same chain in 2011.

We followed the same process for the adolescent sample; however, we selected only from restaurants within one mile of a high school. Again, we randomly selected 10 restaurants in each city, stratified by chain, for a total of 40 restaurants: three McDonald's, two Burger Kings, two Subways, two Dunkin' Donuts, and one Wendy's in each city. Of the initial 40 restaurants, we excluded one restaurant because of management prohibition in 2010, one because of a closure in 2011, and nine because there were no available adolescents to survey on repeated visits in 2010 and 2011. We replaced these restaurants in the same manner as for the adult/school age children sample.

For the adult and school age children samples, we collected surveys together between $515 \mathrm{pm}$ and $730 \mathrm{pm}$, from April through August 2010 and 2011. We chose dinnertime (evening) because collection at lunchtime could have restricted the sample primarily to working adults and provided limited opportunity to sample school age children accompanying their parents or legal guardians. We planned six separate visits to each restaurant to sample a broad representation of diners, but on some of the visits, we collected few or no surveys because of limited traffic and non-response. We made additional visits to those restaurants for a total of 269 visits to the 42 restaurants, including the two in 2010 that we had to replace in 2011.
For the adolescent sample, we collected surveys from noon to $2 \mathrm{pm}$ after the start of school summer break in each city, June through August 2010 and 2011. We also collected an after school sample in Boston only, at the same restaurants as for the lunchtime sample, from $215 \mathrm{pm}$ to $430 \mathrm{pm}$, April through June 2010 and 2011. Because we targeted adolescents unaccompanied by parents, we chose lunchtime or after school for data collection. We chose restaurants near schools to maximize respondents, assuming summer activities near schools. We anticipated six visits to each restaurant but made additional visits if we collected few or no surveys. Because we visited the Boston restaurants both during the school year and over the summer, we planned 12 visits to each restaurant there. We completed a total of 356 visits to the 47 restaurants, including the seven in 2010 that we had to replace in 2011.

\section{Participants}

One or two research assistants administered surveys to customers, typically outside the entrance to the restaurants or on a nearby public sidewalk. The research assistants approached all customers who seemed to meet inclusion criteria: those aged $\geq 18$ for the adult sample, those aged 11-20 for the adolescent sample; and those aged 3-15, and accompanied by a parent or legal guardian, for the school age children sample. Children aged 11-15 were eligible for either the adolescent or school age children sample, depending on the time of day. For the adolescent sample, we interviewed the person directly at lunchtime. For the school age children, we interviewed their accompanying parent or legal guardian at dinnertime about the child's meal. We conducted interviews for the adult and school age children sample during the same restaurant visits, but parents interviewed for the school age children sample were ineligible for the adult sample.

Research assistants approached potential participants as they entered the restaurant and requested their enrollment in a study about "food choices in fast-food restaurants" and asked them to keep their receipt on exit. After collecting the receipt, the research assistants asked each participant to identify which items on the receipt he or she purchased for personal consumption or for their child in the case of the school age children. Additional details on food and beverage choices came from an "item questionnaire" that queried details that were unclear on the receipt, such as whether items were shared, the use of sauces/condiments, the addition of cheese, the type of salad dressing, and specific beverage choices. Research assistants also administered a short questionnaire to gather participants' open ended estimation of their meal's calorie content; responses to questions about how important taste, calories, convenience ("quick to eat"), or price was in food choice ("a lot," "a little," or "not at all"), and awareness and use of nutritional information in the restaurant ("yes," "no," "unsure"); and age, sex, race/ethnicity, height, and weight. Participants self identified race/ethnicity as "white," "black," "Hispanic," "Asian," and/or "other." Research assistants further asked participants to estimate their average daily calorie requirement, selected from a list of multiple choice answers. We categorized answers into a wide range of possibly "correct" values of 1000 to 3000 calories, $<1000$ calories as "incorrectly underestimated," and >3000 calories as "incorrectly overestimated." The research assistants interviewed participants in English; questionnaires translated into Spanish were available to guide participants with limited proficiency in English. We gave a $\$ 2(£ 1.30, € 1.50)$ gift card to each participant for completing the study. We had no explicit exclusion criteria; however, diners who spoke only Spanish 
could not participate because questionnaires were administered only in English.

Research assistants collected data on 1894 adults, 1180 adolescents, and 333 school age children. We excluded 17 adults, two adolescents, and three school age children (less than $1 \%$ ) because we did not collect adequate information to calculate the actual calorie content of their meals. Our final sample size was 1877 adults, 1178 adolescents, and 330 school age children. We counted all potential participants and recorded their sex if they were asked to participate but refused to do so. Among the non-responders we also counted those participants who initially agreed to participate but did not keep their receipt. Of all individuals that we approached, $40 \%$ of adults, $42 \%$ of adolescents, and $45 \%$ of parents with school age children agreed to participate. In each sample the sex ratio of participants (males to females $60: 40,51: 49,53: 47)$ was similar to that of non-participants $(57: 43,51: 49,48: 52)$.

As we classified energy content as calories this is how we have presented it throughout the paper. One calorie is equivalent to $4.18 \mathrm{~kJ}$ (the SI unit).

\section{Analysis}

We calculated the actual calorie content of meals by linking the items on the receipt, clarified by the "item questionnaire," to the calorie content of items listed on restaurant websites. We coded outlier actual or estimated calories as missing if the values exceeded 4000 calories ( 23 adults, 18 adolescents, and no school age children).

\section{Primary analysis: model 1, overall differences}

We used linear regression models to analyze associations with estimated calorie content. In this set of models, we examined estimated calories as the outcome and actual calorie content as the sole predictor. We accounted for clustering by chain (McDonald's, Burger King, Wendy's, KFC, Dunkin' Donuts, and Subway) and by restaurant (identified by the address of each restaurant) with the inclusion of random intercepts for both chain and restaurant. We log transformed estimated and actual meal calorie content because the data were substantially right skewed. We centered the predictor actual calorie content on its mean. Thus, the exponentiated intercepts from these models are the geometric means of the estimated calorie content at the mean actual calorie content. To ensure comparability across models, we included only participants with complete data on all covariates from the second set of models, described below.

\section{Secondary analysis: model 2, factors associated with estimated calorie content}

In these models, we added multiple other predictors of estimated calorie content to model 1, including body mass index (BMI), age, sex, race/ethnicity, restaurant chain; how important taste, calories, convenience, or price were in food choices; whether participants noticed calorie information in the restaurant; and accuracy of estimates of daily calorie requirement. We included these covariates because of a priori hypotheses that these variables might be related to calorie estimation. Because we included chain as a predictor in these models, we used random intercepts only for the restaurants; we removed the random intercept for chains. Because we used a log transformation of estimated calories, the exponentiated parameter estimate is the relative change in estimated calorie content per unit increase for linear predictors or compared with a reference group for categorical predictors.
All analyses were conducted with SAS 9.3 (Cary, NC). We performed sensitivity analyses for all outcomes using multiple imputation procedures to account for all missing and outlier data. ${ }^{67}$ Because results were similar, we report only observed findings.

\section{Results}

Most participants (1161 (62\%) adults, 958 (82\%) adolescents, and $262(81 \%)$ school age children) were non-white (table $1 \Downarrow$ ). Among the adult participants who provided self reported height and weight, $1173(65 \%)$ were either overweight or obese (BMI $\geq 25$ ), as were 388 (34\%) adolescents and 161 (57\%) school age children (BMI $\geq 85$ th centile based on 2000 US Centers for Disease Control and Prevention (CDC) age and sex specific reference data). Over $40 \%$ of participants in each sample ate at the chain restaurant where they were interviewed at least once a week. When asked whether they noticed calorie information in the restaurant, $410(22 \%), 163(14 \%)$, and $51(15 \%)$ responded "yes", but only 88 (5\% of total), $28(2 \%)$, and 14 $(4 \%)$ reported that they used the information to help guide their purchases.

The mean (SD) actual calorie content of meals purchased was 836 calories (465), 756 calories (455), and 733 calories (359), respectively for adult, adolescent, and school age child participants (equivalent to 3494 (1943), 3160 (1901), 3064 (1501) kJ) (table 2). $\Downarrow$ At least two thirds of all participants underestimated the calorie content of their meals, with about a quarter underestimating the calorie content by at least 500 calories. The mean difference between estimated and actual meal calorie content showed that participants underestimated calorie content by 175 calories (95\% confidence interval 145 to 205 calories), 259 calories ( 227 to 291 calories), and 175 calories (108 to 242 calories). The mean underestimation of calorie content was larger among Subway diners than those at other chains for adults (349 calories, 293 to 406 calories) and adolescents ( 500 calories, 429 to 571 calories) with similar values for all chains among school age children (fig $1 \Downarrow$ ). With McDonald's diners as the reference, adult diners at Subway $(\mathrm{P}<0.001)$ and Burger King $(\mathrm{P}=0.01)$ showed greater underestimation of meal calorie content as did adolescent Subway diners $(\mathrm{P}<0.001)$. Adolescent diners at Dunkin' Donuts had less underestimation of meal calorie content than McDonald's diners $(\mathrm{P}=0.008)$.

\section{Primary and secondary analyses Primary analysis: model 1, overall differences}

When we examined the relation between the logs of actual and estimated calorie content across all chains, accounting for clustering by chain and restaurant, the exponentiated intercepts were 372 calories ( $95 \%$ confidence interval 345 to 402 calories), 268 calories ( 238 to 298 calories), and 321 calories (265 to 384 calories) for adults, adolescents, and school age children, respectively (table $3 \Downarrow$ ). These values are the geometric means of estimated calorie content for participants consuming meals of mean actual calorie content. The geometric means are less than a half of the mean actual calorie content, which shows the underestimation of calorie content.

\section{Secondary analysis: model 2, factors associated with estimated calorie content}

In this set of models (table $4 \Downarrow$ and appendix table), we found a linear association between the logs of actual and estimated calorie content in all samples, with much larger underestimates 
for larger meals. To show this graphically, we plotted fixed actual calorie contents of meals versus predicted estimated calorie content, calculated from these fully adjusted models for participants with covariates at reference values or means (fig $2 \Downarrow)$.

Adult and adolescent participants dining at Subway estimated $20 \%$ and $25 \%$ lower meal calorie content than those dining at McDonald's (relative change 0.80 (95\% confidence interval 0.66 to 0.96 ) for adults and 0.75 (0.57 to 0.99 ) for adolescents; table $4 \Downarrow$ ). In other words, diners at Subway underestimated calorie content by more than diners at McDonald's. Failure to notice calorie information in the restaurant was not associated with calorie estimates for any of the samples. Underestimation of personal total daily calorie requirements was associated with lower estimated meal calorie content for each sample compared with a "correct" assessment of requirement $(0.44$ (95\% confidence interval 0.38 to 0.52 ) for adults; 0.50 (0.42 to 0.59$)$ for adolescents; and 0.39 ( 0.27 to 0.57 ) for parents of school age children)

Adults with higher BMI estimated higher calorie content of meals (1.12 (95\% confidence interval 1.06 to 1.17$)$ per BMI points) and, thus, were less likely to underestimate calorie content (table $4 \Downarrow$ ). Among adults, older participants estimated lower calorie content $(0.91$ ( 0.88 to 0.95$)$ per 10 years), meaning that for every additional 10 years of age, participants estimated 9\% lower calorie content compared with the younger adults. In contrast, older adolescents estimated higher calorie content than younger adolescents, which shows a lower likelihood of underestimation (1.04 (1.02 to 1.08) per year). Black, Hispanic, Asian, and "other" race/ethnicity or multiracial adults and adolescents estimated lower meal calorie content than white participants.

\section{Discussion}

In this study of diners at fast food chain restaurants in four New England cities, we found that participants purchased large meals, and adults, adolescents, and (parents of) school age children underestimated the calorie content of those meals by 175 calories, 259 calories, and 175 calories, respectively. Nearly a quarter of adults, adolescents, and (parents of) school age children underestimated meal calorie content by 500 or more calories. Estimated calorie content was strongly associated with actual calorie content for each of the samples. Noticing calorie information in the restaurant had no effect on the accuracy of calorie estimations.

In a study of 147 fast food restaurant diners at food courts, Chandon and Wansink also found that people underestimated the calorie content of purchased meals, with larger underestimation for higher calorie meals and no association with recognition of nutritional information in the restaurants. ${ }^{2}$ Compared with that study and other previous research, ${ }^{14}$ our study has the advantages of a large sample size, comparison of diners at six restaurant chains across four cities, recruitment of a racially and ethnically diverse study population in three age groups, and investigation of predictors of underestimation.

Adult and adolescent diners at Subway restaurants estimated lower calorie content than diners at the other chains. These findings suggest a consistent "health halo" for Subway in these age groups. In a study of 518 participants eating meals with equivalent calorie content at McDonald's and Subway, Chandon and Wansink found that participants estimated 151 fewer calories at Subway than at McDonald's. ${ }^{3}$ Participants also ordered side dishes with more calories at Subway. Dieticians also falsely considered equivalent calorie meals to be lower calorie at Subway than McDonald's. ${ }^{3}$ Our study extends these findings by showing that this "health halo" is unique to Subway across the six chains and is present across age groups in a diverse sample.

Branding could be an important component of Subway's "health halo." Marketing researchers have found that brand positioning is particularly important in guiding consumer choices when specific information about products is not available. ${ }^{8}$ For example, simply labeling a food item as "heart healthy" led consumers in one experiment to conclude that the item conferred a lower risk of heart disease and stroke than similar unlabeled foods. ${ }^{9}$ Subway's positioning as a "healthier" fast food option might lead consumers to view its food as lower calorie, especially when calorie information is not readily apparent.

The forthcoming US federal regulation on labeling calorie content on menus could alter this "health halo" by providing easily accessible information on menus and menu boards. ${ }^{10} 11$ Previous research has found that information can be most powerful when it contradicts previous expectations (in this case, improper estimation of calorie content of foods with a "health halo"). ${ }^{12}$ Unlike previous state and local regulations, the federal regulation will also require an anchoring statement that indicates recommended total daily calorie requirements. In our study, participants' estimates of meal calories strongly correlated with their estimates of total daily requirements, supporting inclusion of daily requirements on menus as an "anchor." Thus far, research about the effects of calorie menu labeling, in both real world and experimental settings, has been mixed. ${ }^{13-26}$ It is difficult to ascertain why these studies had inconsistent results, but differing study designs, demographic characteristics, the rare use of an anchoring statement, and weight status might be involved.

In addition to providing an anchoring statement on menus, policymakers could perhaps improve menu labeling by supporting social marketing campaigns to better explain the concept of calories. These efforts could bolster not only menu labeling but nutritional labeling of packaged foods.

\section{Limitations of study}

There are several limitations to our study. First, because more than half of eligible individuals did not participate, the participants in our study might not represent all customers of the restaurants. It is somewhat reassuring that the sex ratio of respondents and non-respondents was similar, but sex was the only information that we were able to collect on non-respondents. While our response rate seems low, this rate was higher than we anticipated for the fast paced environments where we collected data. The low response could bias the results in either direction. Participants who did not have time to respond to our survey might also have been less aware of nutritional information in restaurants than those who did respond. Thus, our respondents might represent a group less likely to underestimate, biasing our results toward the null. In contrast, some potential participants with higher education, perhaps better able to estimate calorie content, might have ignored our monetary incentive. As a result, our respondents might have been less aware of calorie content than the overall population, biasing our results away from the null. Telephone or household surveys could have yielded higher response rates but would not allow collection of receipts needed to objectively determine the calorie content of meals. Second, we could not sample customers in the drive through section of restaurants, whose behavior might differ from that of walk in customers. Third, we could not measure actual calorie consumption by weighing food before 
and after consumption, as would be possible in a laboratory setting. Instead, we collected receipts and asked detailed questions about items participants purchased for their personal consumption. Fourth, because we developed the questionnaire to be brief, we collected only basic demographic information, height, and weight on participants. We were unable to collect additional health information that could affect estimation of calorie content.

\section{Conclusion}

In this study of over 3000 diners at six fast food restaurant chains across four diverse New England cities, we found that adults, adolescents, and parents of school age children generally underestimated the calories of meals, especially if the meal was large. Adults and adolescents dining at Subway underestimated calorie content more than diners at other chains. The forthcoming calorie menu labeling requirements of the US Patient Protection and Affordable Care Act might help to correct underestimation of calorie content.

We thank Angela Bannister, Anthony Bean, Deborah Burton, Alanna Burwell, Hilda Castillo, Jamie Chachere, Alicia Johnson, Elise Lauer, Rose Nabehet, Christine Orcutt, Diedra Oretade, Liberty Pande, Maricelle Ramirez, Elyse Rohrer, and Jordan Warner for their help with data collection.

JPB presented some results from this study at the Annual Meeting of the Society of General Internal Medicine in May 2011, the Annual Meeting of The Obesity Society in October 2011, and the Annual Meeting of The Obesity Society in September 2012.

Contributors: JPB, SKC, KK, JM, SL, and MWG conceptualized the study design and the data collection strategy. JPB, KK, and SR-S conducted the data analyses, and MWG provided critical feedback on the analyses. JPB drafted the manuscript, and SKC, KK, JM, SL, SR-S, and $M W G$ revised the manuscript. All authors approved the final version of the manuscript. JPB is guarantor.

Funding: The study was funded by a P30 center grant from the National Heart, Lung, and Blood Institute (P30 HL101312-01, PI: Gillman), a Robert Wood Johnson Foundation Health and Society Scholars seed grant from the Harvard University site (PI: Block), the Robert Wood Johnson Foundation Healthy Eating Research program (grant 70739, PI: Block), and the Robert $\mathrm{H}$ Ebert Fellowship, funded by the Harvard Pilgrim Health Care Foundation through the Eleanor and Miles Shore Fellowship Program at Harvard Medical School (PI: Block). The sponsors of this study had no role in the study design, data collection, or analysis for this study and did not require final approval of the manuscript.

Competing interests: All authors have completed the ICMJE uniform disclosure form at www.icmje.org/coi_disclosure.pdf (available on request from the corresponding author) and declare: JPB, KK, SL, SR-S received salary support from the National Heart, Lung, and Blood Institute (NIH) for the submitted work; JPB, SL, and SR-S received support from the Robert Wood Johnson Health Eating Research program; and JPB and SL received support from the Ebert Fellowship. Ethical approval: The study was approved by the institutional review board of Harvard Pilgrim Health Care (approval 0311). Because data collection was anonymous and queried non-sensitive information, the board approved this study without requiring written informed consent from participants. For the same reasons, the board also granted permission for us to interview those aged 11-20, included in the adolescent sample, without parental consent.

Data sharing: No additional data available.

1 Burton S, Creyer EH, Kees J, Huggins K. Attacking the obesity epidemic: the potential health benefits of providing nutrition information in restaurants. Am J Public Health 2006:96:1669-75.

2 Chandon $P$, Wansink B. Is obesity caused by calorie underestimation? a psychophysical model of fast-food meal size estimation. Journal of Marketing Research 2007;44:84-99. Chandon P, Wansink B. The biasing health halos of fast food restaurant health claims: lower calorie estimates and higher side-disk consumption intentions. Journal of Consumer Research 2007:34:301-14

4 Elbel B. Consumer estimation of recommended and actual calories at fast food restaurants. Obesity (Silver Spring) 2011;19:1971-8.

5 Elbel B, Gyamfi J, Kersh R. Child and adolescent fast-food choice and the influence of calorie labeling: a natural experiment. Int J Obes (Lond) 2011;35:493-500.

6 Horton NJ, Kleinman KP. Much ado about nothing: a comparison of missing data methods and software to fit incomplete data regression models. Am Stat 2007:61:79-90.

7 Little RJ, Rubin DB. Statistical analysis with missing data. 2nd ed. Wiley, 2002.

8 Ross WT, Creyer EH. Making inferences about missing information: the effects of existing information. Journal of Consumer Research 1992;19:14-25.

9 Kozup JC, Creyer EH, Burton S. Making healthful food choices: the influence of health claims and nutrition information on consumers' evaluations of packaged food products and restaurant menu items. Journal of Marketing 2003;67:19-34.

10 US Department of Health and Human Services, US Food and Drug Administration. Disclosure of nutrient content information for standard menu items offered for sale at chain restaurants or similar retail food establishments or for articles of food sold from vending machines. Fed Regist 2010;75:39026-28.

11 Variyam J. Nutrition labeling in food-away-from-home sector: an economic assessment. Economic Research Service, United States Department of Agriculture, 2005.

12 Van Raaij WF. The formation and use of expectations in consumer decision making. In: Robertson TS, Kassarjian HH, eds. Handbook of consumer behavior. Prentice Hall, 1991:401-18.

13 Larson N, Story M. Menu labeling: does providing nutrition information at the point of purchase affect consumer behavior? A research synthesis. Robert Wood Johnson Foundation, Healthy Eating Research, 2009.

14 Cinciripini P. Changing food selections in a public cafeteria: an applied behavior analysis. Behav Modif 1984;8:520-39.

15 Milich R, Anderson J, Mills M. Effects of visual presentation of caloric values on food buying by normal and obese persons. Percept Mot Skills 1976;42:155-62.

16 Balfour D, Moody R, Wise A, Brown K. Food choice in response to computer-generated nutrition information provided about meal selections in workplace restaurants. J Hum Nutr Diet 1996;9:231-7.

17 Davis-Chervin D, Rogers T, Clark M. Influencing food selection with point-of-choice nutrition information. J Nutr Educ 1985;17:18-22.

18 Yamamoto JA, Yamamoto JB, Yamamoto BE, Yamamoto LG. Adolescent fast food and restaurant ordering behavior with and without calorie and fat content menu information. $J$ Adolesc Health 2005;37:397-402.

19 Gerend MA. Does calorie information promote lower calorie fast food choices among college students? J Adolesc Health 2009;44:84-6.

20 Dumanovsky T, Huang CY, Nonas CA, Matte TD, Bassett MT, Silver LD. Changes in energy content of lunchtime purchases from fast food restaurants after introduction of calorie labelling: cross sectional customer surveys. BMJ 2011;343:d4464.

21 Mayer J, Brown T, Heins J, Bishop D. A multi-component intervention for modifying food selections in a worksite cafeteria. J Nutr Educ 1987;19:277-80.

22 Harnack LJ, French SA, Oakes JM, Story MT, Jeffery RW, Rydell SA. Effects of calorie labeling and value size pricing on fast food meal choices: Results from an experimental trial. Int J Behav Nutr Phys Act 2008;5:63.

23 Finkelstein EA, Strombotne KL, Chan NL, Krieger J. Mandatory menu labeling in one fast-food chain in King County, Washington. Am J Prev Med 2011;40:122-7.

24 Elbel B, Kersh R, Brescoll V, Dixon B. Calorie labeling and food choices: a first look at the effects on low-income people in New York City. Health Aff (Millwood) 2009;28:w1110-21.

25 Aron J, Evans R, Mela D. Paradoxical effects of a nutrition labeling scheme in a student cafeteria. Nutrition Research 1995;15:1251-61.

26 Roberto CA, Larsen PD, Agnew H, Baik J, Brownell KD. Evaluating the impact of menu labeling on food choices and intake. Am J Public Health 2009;100:312-8.

Accepted: 25 April 2013

\section{Cite this as: BMJ 2013;346:f2907}

This is an Open Access article distributed in accordance with the Creative Commons Attribution Non Commercial (CC BY-NC 3.0) license, which permits others to distribute, remix, adapt, build upon this work non-commercially, and license their derivative works on different terms, provided the original work is properly cited and the use is non-commercial. See: http://creativecommons.org/licenses/by-nc/3.0/. 


\section{What is already known on this topic}

Consumers are known to underestimate the calorie content of restaurant meals, especially for large calorie meals

Previous studies have been conducted in experimental settings without monitoring consumer choices at actual fast food restaurants, have focused on a narrow range of fast food restaurants, or have enrolled samples with limited racial/ethnic or age group diversity

\section{What this study adds}

All age groups and racial/ethnic groups studied underestimated the calorie content of meals from fast food restaurants

\section{Tables}

Table 1/ Characteristics of participants purchasing meals from fast food restaurant chains in four cities in New England, US, 2010 and 2011, and responses to questionnaire items. Figures are numbers (percentage) of participants unless stated otherwise

\begin{tabular}{|c|c|c|c|}
\hline Variables & Adults $(n=1877)$ & Adolescents ( $n=1178$ ) & School age children $(n=330)$ \\
\hline Mean (SD; range) age (years) & $37.2(16.1 ; 18-87)$ & $16.1(2.8 ; 11-20)$ & $7.9(3.2 ; 3-15)$ \\
\hline Mean (SD; range) BMI & $27.9(6.2 ; 16.7-56.2)$ & $23.4(4.8 ; 13.6-64.7)$ & $21.1(6.6 ; 10.8-54.5)$ \\
\hline Male & $1069(57)$ & $597(51)$ & $155(48)$ \\
\hline Female & $803(43)$ & $579(49)$ & $169(52)$ \\
\hline White & $704(38)$ & $217(18)$ & $61(19)$ \\
\hline Black & $578(31)$ & $401(34)$ & $108(33)$ \\
\hline Hispanic & $343(18)$ & $323(27)$ & $98(30)$ \\
\hline Asian & $74(4)$ & $79(7)$ & $9(3)$ \\
\hline Other or multiple race & $166(9)$ & $155(13)$ & $47(15)$ \\
\hline \multicolumn{4}{|l|}{ Taste important in food choice: } \\
\hline A lot & $1490(79)$ & $861(73)$ & $283(86)$ \\
\hline A little & $296(16)$ & $248(21)$ & $40(12)$ \\
\hline Not at all & $91(5)$ & $67(6)$ & $7(2)$ \\
\hline \multicolumn{4}{|l|}{ Calories important in food choice: } \\
\hline A lot & $475(25)$ & $244(21)$ & $102(31)$ \\
\hline A little & $476(25)$ & $369(31)$ & $90(27)$ \\
\hline Not at all & $923(49)$ & $562(48)$ & $137(42)$ \\
\hline \multicolumn{4}{|l|}{ Price important in food choice: } \\
\hline A lot & $620(33)$ & $217(18)$ & $84(25)$ \\
\hline A little & $576(31)$ & $421(36)$ & $107(32)$ \\
\hline Not at all & $681(36)$ & $539(46)$ & $139(42)$ \\
\hline \multicolumn{4}{|c|}{ Quick to eat important in food choice: } \\
\hline A lot & $992(53)$ & $367(31)$ & $136(41)$ \\
\hline A little & $483(26)$ & $394(33)$ & $96(29)$ \\
\hline Not at all & $400(21)$ & $416(35)$ & $98(30)$ \\
\hline \multicolumn{4}{|c|}{ Noticed calorie information in restaurant: } \\
\hline Yes & $410(22)$ & $163(14)$ & $51(15)$ \\
\hline No & $1337(71)$ & $880(75)$ & $249(75)$ \\
\hline Unsure & $129(7)$ & $135(11)$ & $30(9)$ \\
\hline \multicolumn{4}{|c|}{ Personal estimate of daily calorie* requirement: } \\
\hline Accurate $(1000-3000$ calories/ & $1376(74)$ & $790(67)$ & $194(60)$ \\
\hline Underestimated $(<1000$ caloric & $341(18)$ & $276(23)$ & $111(34)$ \\
\hline Overestimated $(>3000$ calories & $143(8)$ & $110(9)$ & $21(6)$ \\
\hline
\end{tabular}


Table 2| Characteristics of participants' meals purchased at fast food restaurant chains in four cities in New England, US, 2010 and 2011, included in study of consumers' estimates of calorie content of meals. Figures are numbers (percentage) unless stated otherwise

\begin{tabular}{|c|c|c|c|}
\hline & Adults $(n=1877)$ & Adolescents ( $n=1178$ ) & School age children $(n=330)$ \\
\hline \multicolumn{4}{|l|}{ Restaurant chain: } \\
\hline McDonald's & $606(32)$ & $524(44)$ & $144(44)$ \\
\hline Burger King & $530(28)$ & $268(23)$ & $102(31)$ \\
\hline Subway & $345(18)$ & $115(10)$ & $26(8)$ \\
\hline $\mathrm{KFC}$ & $195(10)$ & - & $35(11)$ \\
\hline Wendy's & $201(11)$ & $120(10)$ & $23(7)$ \\
\hline Dunkin' Donuts & - & $151(13)$ & - \\
\hline \multicolumn{4}{|l|}{ Calorie $^{*}$ content of meals: } \\
\hline Mean (SD; range) actual content & $836(465 ; 0-3410)$ & $756(455 ; 0-2980)$ & $733(359 ; 94-2170)$ \\
\hline Median (IQR) actual content & $790(480,1130)$ & $698(406,1070)$ & $670(510,920)$ \\
\hline Mean (SD; range) estimated content & $649(622 ; 0-3600)$ & $490(521 ; 0-3883)$ & $562(569 ; 0-4000)$ \\
\hline Median (IQR) estimated content & $500(200-950)$ & $300(120-650)$ & $400(200-800)$ \\
\hline \multicolumn{4}{|c|}{ Difference between estimated and actual calorie content: } \\
\hline Mean (SD, range) & $-175(637,-2410-2672)$ & $-259(551,-2380-2945)$ & $-175(590,-2060-2750)$ \\
\hline Median (IQR) & $-190(-550-80)$ & $-260(-555--30)$ & $-220(-470-40)$ \\
\hline
\end{tabular}


Table 3| Mean estimated meal calorie content among participants purchasing meals at fast food restaurant chains in four cities in New England, US, 2010 and 2011*

\begin{tabular}{|c|c|c|}
\hline Variables & Parameter estimate $(95 \% \mathrm{Cl})$ & Exponentiated parameter estimate† $(95 \% \mathrm{Cl})$ \\
\hline \multicolumn{3}{|l|}{ Adults } \\
\hline Intercept† & $5.92(5.84$ to 6.00$)$ & 372 (345 to 402$)$ \\
\hline Log actual calorie content, relative change & 0.57 (0.50 to 0.63$)$ & 1.77 (1.65 to 1.88$)$ \\
\hline \multicolumn{3}{|l|}{ Adolescents } \\
\hline Intercept† & $5.59(5.47$ to 5.70$)$ & 268 (238 to 298) \\
\hline Log actual calorie content, relative change & 0.51 (0.42 to 0.59$)$ & 1.67 (1.53 to 1.81$)$ \\
\hline \multicolumn{3}{|l|}{ School age children } \\
\hline Intercept† & 5.77 (5.58 to 5.95$)$ & 321 (265 to 384$)$ \\
\hline Log actual calorie content, relative change & 0.39 (0.08 to 0.70$)$ & 1.48 (1.09 to 2.01$)$ \\
\hline \multicolumn{3}{|c|}{$\begin{array}{l}\text { *1658 adult, } 1081 \text { adolescent, and } 254 \text { school age participants had complete data on all covariates examined in multivariable regression models (shown in table } \\
4) ; \text { we used this sample for these models. } \\
\text { †Parameter estimates of intercept are arithmetic means of estimated calorie content on log scale. Because we log transformed outcome of estimated calories and } \\
\text { centered predictor log actual calorie content on its mean, exponentiated intercepts are geometric means of estimated calorie content for those participants consuming } \\
\text { meals of mean actual calorie content ( } 836,756 \text {, and } 733 \text { calories for adults, adolescents, and school age children). Geometric means of estimated calorie conten } \\
\text { are less than half of mean actual calorie content of meals. }\end{array}$} \\
\hline
\end{tabular}


Table 4| Predictors of estimated calorie content among participants purchasing meals at fast food restaurant chains in four cities in New England, US, 2010 and 2011. * Figures are relative changet $(95 \% \mathrm{Cl})$

\begin{tabular}{|c|c|c|c|}
\hline Variables & Adults & Adolescents & School age children \\
\hline $\begin{array}{l}\text { Intercept (estimated calorie content for } \\
\text { meal of mean actual calorie content) }\end{array}$ & 459 (298 to 707 ) & 148 (75.1 to 295$)$ & 372 (55.6 to 2485$)$ \\
\hline $\begin{array}{l}\text { Log actual calorie content (centered on } \\
\text { log mean) }\end{array}$ & $1.73(1.62$ to 1.84$)$ & $1.60(1.47$ to 1.74$)$ & 1.57 (1.14 to 2.18$)$ \\
\hline Age (per year) & $0.91 \ddagger(0.88$ to 0.95$)$ & 1.04 (1.02 to 1.08$)$ & 0.99 (0.93 to 1.05$)$ \\
\hline BMI (per 5 points) & 1.12 (1.06 to 1.17$)$ & 1.06 (0.98 to 1.14$)$ & $0.96(0.84$ to 1.10$)$ \\
\hline \multicolumn{4}{|l|}{ Sex: } \\
\hline Female & 1.0 (ref) & 1.0 (ref) & 1.0 (ref) \\
\hline Male & 0.95 (0.85 to 1.07$)$ & $0.92(0.80$ to 1.07$)$ & 1.36 (0.96 to 1.92$)$ \\
\hline \multicolumn{4}{|l|}{ Race/ethnicity: } \\
\hline White & 1.0 (ref) & 1.0 (ref) & 1.0 (ref) \\
\hline Asian & 0.74 (0.55 to 1.00$)$ & 0.64 (0.46 to 0.88$)$ & $1.45(0.45$ to 4.64$)$ \\
\hline Black & $0.66(0.57$ to 0.76$)$ & 0.68 (0.55 to 0.85$)$ & $1.07(0.64$ to 1.81$)$ \\
\hline Hispanic & 0.71 (0.60 to 0.84$)$ & 0.64 (0.51 to 0.80$)$ & 0.91 (0.54 to 1.50$)$ \\
\hline Other or multiracial & $0.70(0.57$ to 0.87$)$ & 0.68 (0.53 to 0.88$)$ & $1.42(0.79$ to 2.55$)$ \\
\hline \multicolumn{4}{|l|}{ Restaurant chain: } \\
\hline McDonald's & 1.0 (ref) & 1.0 (ref) & 1.0 (ref) \\
\hline Burger King & 1.01 (0.86 to 1.18$)$ & 1.17 (0.96 to 1.44$)$ & $1.14(0.71$ to 1.81$)$ \\
\hline Wendy's & $1.01(0.81$ to 1.25$)$ & 1.19 (0.91 to 1.56$)$ & $0.83(0.40$ to 1.68$)$ \\
\hline $\mathrm{KFC}$ & 1.20 (0.96 to 1.50$)$ & - & 1.45 (0.75 to 2.80$)$ \\
\hline Subway & 0.80 (0.66 to 0.96$)$ & 0.75 (0.57 to 0.99$)$ & 0.91 (0.46 to 1.82$)$ \\
\hline Dunkin' Donuts & - & 0.83 (0.65 to 1.06$)$ & - \\
\hline Type $3 \mathrm{~F}$ test for chain difference & $P=0.02$ & $P=0.01$ & $P=0.71$ \\
\hline \multicolumn{4}{|l|}{ Noticed posted calories in restaurant: } \\
\hline Yes & 1.0 (ref) & 1.0 (ref) & 1.0 (ref) \\
\hline No & $0.89(0.77$ to 1.03$)$ & 0.94 (0.76 to 1.17$)$ & $0.88(0.54$ to 1.45$)$ \\
\hline Unsure & $0.77(0.60$ to 0.99$)$ & $0.83(0.62$ to 1.10$)$ & $0.91(0.44$ to 1.90$)$ \\
\hline \multicolumn{4}{|c|}{ Personal estimate of daily calorie requirement: } \\
\hline Accurate (1000-3000 calories/day) & 1.0 (ref) & 1.0 (ref) & 1.0 (ref) \\
\hline Underestimated (<1000 calories/day) & $0.44(0.38$ to 0.52$)$ & $0.50(0.42$ to 0.59$)$ & $0.39(0.27$ to 0.57$)$ \\
\hline Overestimated (>3000 calories/day) & $1.13(0.91$ to 1.41$)$ & 1.27 (0.98 to 1.63$)$ & $1.48(0.71$ to 3.05$)$ \\
\hline
\end{tabular}

*Model is adjusted for all of variables in table as well as factors important in food choices (see appendix table for results for these variables). 1658 adults, 1081 adolescents, and 254 school age children had complete data on all variables. Results from multiple imputation models with all participants (1877, 330,1178 ) were similar to results shown.

†Because we log transformed estimated calories, exponentiated parameter estimates are relative changes in estimated calorie content per unit increase for linear predictors or compared with reference group for categorical predictors.

$\ddagger$ Parameter estimate is per 10 years in this model rather than per year. 


\section{Figures}

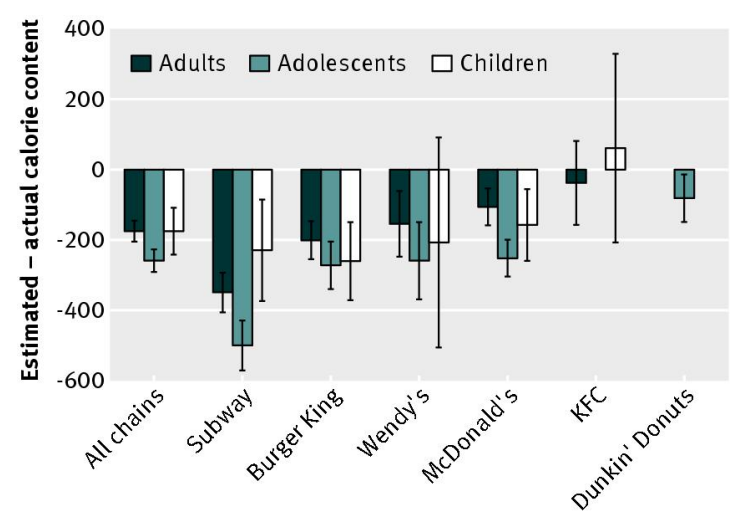

Fig 1 Mean difference between estimated and actual calorie content of purchased meals, by restaurant chain, at fast-food restaurants in four cities in New England, 2010 and 2011

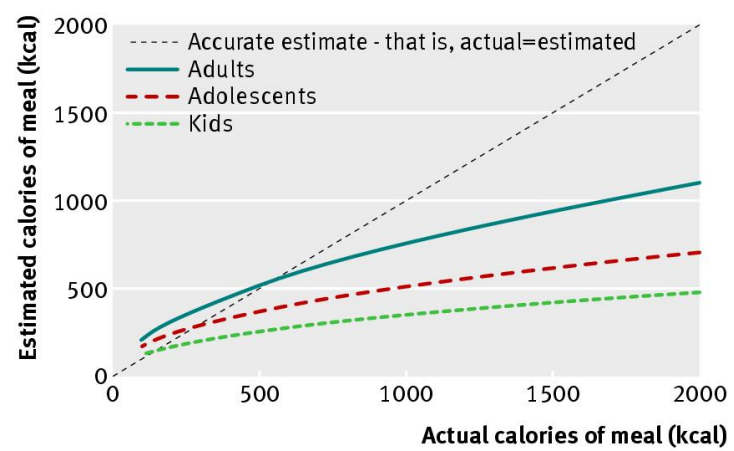

Fig 2 Estimated calorie content versus actual calorie content of meals among adults, adolescents, and school age children in fast food restaurants in four cities in New England, 2010 and 2011. Figure shows predicted estimated calorie content, calculated from fully adjusted models for participants with covariates at reference values or means, at fixed values for actual meal calorie content. Underestimation of calorie content of meals was greater with larger meals for each of samples 